\title{
Further evidence on the dependence between reinforcing and discriminative functions of a stimulus
}

\author{
Joseph E. Morrow, Lewis B. Sachs and Hobert R. Belair \\ WASHINGTON STATE UNIVERSITY
}

\begin{abstract}
A previous experiment by Ratner (1956) found a brief secondary reinforcing effect of a stimulus in the absence of any discriminative effect. Since these results are contrary to the general line of evidence in this field, an attempt was made in the present study to replicate the findings. The results failed to confirm Ratner's data.

\section{Problem}

The Keller \& Schoenfeld (1950) hypothesis that a stimulus must first serve as a discriminative stimulus in order to have secondary reinforcing properties, has generally been supported by experimental findings (Myers, 1958). The interchangeability of these properties has been suggested by Dinsmoor (1952) as well as by Coate (1956) who found that weakening the $\mathrm{S}^{\mathrm{D}}$ properties of a stimulus also weakened its $\mathrm{S}^{r}$ function. There are many findings consistent with the above mentioned studies, but there is one notable exception. Ratner (1956) has presented data which suggest that a stimulus having once been established as an $\mathrm{S}^{\mathrm{D}}$ for goal approaching may at a subsequent time serve an $\mathbf{S}^{\mathbf{r}}$ function for a bar press without serving as an $\mathrm{S}^{\mathrm{D}}$ for goal approaching. Myers (1958) pointed out the discrepancy of these data with the rest of the literature and suggested an attempt at replication be made. Zimmerman (1959) found a somewhat similar phenomenon where rats after performing a bar press that produced an $\mathrm{Sr}^{\mathrm{r}}$.did not complete the response of running down an alley which had followed the Sr during training. However, in the Zimmerman study, the experimenter then placed the rats back in the presence of the bar, so the results do not represent findings equivalent to Ratner's. There actually exists a paucity of data that either directly support Ratner's findings or have failed to confirm them. It is the purpose of the present study to attempt a replication of the findings of Ratner using a similar methodology.

\section{Method}

Sixteen adapted male albino rats $23 \mathrm{hr}$. food and water deprived were trained to approach a dipper loaded with .1 cc $12 \%$ sucrose solution at the sound of a click. The apparatus was a standard GrasonStadler, 2-bar rat station, model E 3125 D modified in the following manner: Both bars were removed and the resulting holes were covered with unpainted sheet metal. The opening to the dipper area was covered with a $1 / 16$ in clear plastic panel, hinged in a manner to allow access to the dipper when pushed.
Pushing the panel $1 / 2$ in with a force of approximately $10 \mathrm{gm}$ activated a micro-switch thereby registering such goal responses on automatic equipment in an adjacent room. The rat station was housed in a GrasonStadler chest, model E 3125 A.

After preliminary training in which the panel push served as an instrumental response producing the dipper, the Ss were given six days of $\mathrm{S}^{\mathrm{D}}$ training where the dipper was presented for $3 \mathrm{sec}$. uncorrelated with a response, provided a panel push had not occurred for a specified length of time. This time varied from 1 to 4 sec. During training three measures were recorded: (1) the number of panel pushes, (2) the number of dipper presentations not followed by a panel push within $3 \mathrm{sec}$., and (3) the number of panel pushes within $3 \mathrm{sec}$. of the dipper presentation. This last measure was deemed analagous to the "click-water sequence" in the Ratner study and, following Ratner, each daily session was terminated after 17 of these occurred.

After training the Ss were divided for testing on the basis of their performance on the last day of training. The groups were matched on the number of unreinforced panel pushes and the number of dipper presentations not followed by a panel push within $3 \mathrm{sec}$. The experimental group had a mean of 65.63 on the former and 10.25 on the latter. The means of the control group were 66.00 and 10.50 .

During testing, the apparatus was further modified. Bar I was inserted and a "shaping bar" was fitted over the regular bar. This extended downward forming a metal panel for 3 in. Halfway down the panel a $3 / 4$ in bar extended horizontally. During testing a depression of the shaping bar produced the click of the dipper for the E group, but not for the C group. Sucrose was not available during testing. The test sessions began approximately $24 \mathrm{hr}$. after the beginning of the start of the last training day and lasted for $15 \mathrm{~min}$. after the first bar press for each animal. Three measures were recorded: (1) the number of bar presses, (2) the number of goal approaches and (3) the number of goal approaches within $3 \mathrm{sec}$. of a bar press.

\section{Results}

The mean numbers of panel pushes, or goal responses, in $15 \mathrm{~min}$. after the first bar press were 117.00 tor the $\mathrm{E}$ group and 100.25 for the $\mathrm{C}$ group. The mean numbers of bar presses were 17.88 for the $\mathrm{E}$ group and 22.13 for the $\mathrm{C}$ group. The mean numbers 
of goal approaches, within 3 sec. of a bar press, were 1.63 for the $E$ group and 1.13 for the $C$ group. None of these differences approached significance.

\section{Diseussion}

This study failed to find secondary reinforcing effects in the absence of discriminative effects of a stimulus. This finding would be expected in the light of the work of Schoenfeld, Antonitis, \& Bersh (1950) as well as of Dinsmoor (1952), Coate (1956) and others.

A ready explanation of the failure of this study to replicate the findings of Ratner is not apparent.

Ratner's brief report does not mention on what basis the Ss were divided for testing. A random division could possibly have capriciously resulted in a more active control group whose generalized level of goal responses cancelled out the effects of any discriminative operant in the experimental group. The matching of Ss on the basis of degree of discriminative control, in the present study, should have made the occurrence of this unlikely here.

Myers (1958) has suggested that the Ratner results might indicate that the $\mathrm{SD}$ effects extinguished before the $\mathrm{Sr}$ effects. Although some evidence indicates this is not likely (Dinsmoor, 1952; Coate, 1956) this possibility has not, as yet, received adequate test. The present results would argue against Myer's suggestion, however, and lend support to the general line of evidence that points to the necessity of discriminative effects of a stimulus as a precondition to any reinforcing effects it might show.

\section{References}

COATE, W. B. Weakening of conditioned bar-pressing by prior extinction of its subsequent discriminated operant. J. comp. physiol. Psychol., 1956, 49, 135-138.

DINSMOOR, J. A. Resistance to extinction following periodic reinforcement in the presence of a discriminative stimulus. J. comp. physiol. Psychol., 1952, 45, 31-35.

KELLER, F. S., \& SCHOFNFELD, W. N. Principles of psychology. New York: Appleton-Century-Crofts, 1950.

MYFRS, J. L. Secondary reinforcements: a review of recent experimentation. Psychol. Bull., 1958, 55, 284-301.

RATNFR, S. C. Reinforcing and discriminative properties of the click in a Skinner box. Psychol. Rep., 1956, 2, 332.

SCHOENFELD, W. N., ANTONITIS, J. J., \& BERSH, P. J. A preliminary study of training conditions necessary for secondary reinforcement. J. exp. Psychol., 1950, 40, 40-45.

ZIMMERMAN, D. W. Sustained performance in rats based on secondary reinforcement. J. comp. physiol. Psychol., 1959, 52, 353-358.

Note

1. The authors are grateful for the invaluable assistance of Professor J. D. Keehn on this project.

\section{Erratum}

BOSSOM, J. The effect of brain lesions on prismadaptation in monkey. Psychon. Sci., 1965, 2, 45-46.As most readers will probably have recognized, the two figures (but not their legends) were, regrettably, reversed. The picture appearing in Fig. 1 should have been in Fig. 2, and vice versa.-Editor. 